\title{
Idiopathic laryngotracheal stenosis
}

\author{
F. Griffith Pearson, MD
}

See related article on page 99
From the Department of Surgery, Division of Thoracic Surgery, University of Toronto, Toronto General Hospital, Toronto, Ontario, Canada.

Received for publication Jan 21, 2003; accepted for publication Feb 22, 2003.

Address for reprints: F. Griffith Pearson, MD, the Department of Surgery, Division of Thoracic Surgery, University of Toronto, Toronto General Hospital, RR1, Mansfield, Ontario, LON 1M0, Canada.

J Thorac Cardiovasc Surg 2004;127:10-1

$0022-5223 / \$ 30.00$

Copyright () 2004 by The American Association for Thoracic Surgery

doi:10.1016/S0022-5223(03)00580-4

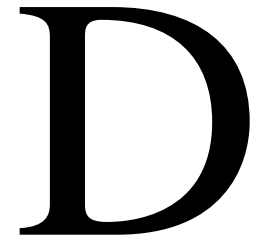

uring the past 40 years, Dr Hermes Grillo and his colleagues have established a center for upper airway surgery that is unique in terms of the volume of clinical experience that has been attracted, managed, and clearly reported on. Their referral cases include every significant condition in this relatively esoteric field. Idiopathic laryngotracheal stenosis (ILTS) is infrequently reported and is one of the least understood upper airway pathologies. There are even fewer published reports of successful management by means of resection and primary reconstruction in a single stage. In this issue Ashiku and colleagues ${ }^{1}$ describe an extensive and detailed review of 73 patients with ILTS, all managed by means of a 1-stage resection and primary anastomosis between 1971 and 2002.

The classic features of ILTS warrant emphasis. ILTS is a relatively uncommon condition of unknown cause characterized by a nonspecific inflammation of the mucus membrane of the upper airway, which can progress to cicatricial and circumferential stenosis of variable severity. The condition is almost exclusively confined to women (71/73 patients) between 20 and 60 years of age. The authors provide a clear, concise description of the clinical presentation (most commonly dyspnea and wheezing respiration), natural history, differential diagnosis, and surgical pathology. The inflammatory lesion and subsequent cicatricial stenosis is found in the upper airway at the subglottic and upper tracheal levels. On occasion, the inflammation extends to the inferior margin of the vocal cords. Spontaneous resolution was not observed, although progression of subglottic stenosis can progress very slowly over periods of many years.

All 73 patients were operated on at a time in the course of their disease when the acute inflammation had subsided and when symptomatic stenosis was not adequately manageable by means of dilation alone. A single-stage operation consisted of circumferential resection of the upper cervical trachea, which included all or part of the anterior cricoid arch in 63 patients. In 36 of these 63 subglottic resections, the cicatricial process extended high in the subglottis and required a resection close to or abutting the inferior margin of the vocal cords. A flap of posterior membranous trachea was fashioned from the distal tracheal resection margin and used to cover the denuded surface of the posterior cricoid plate, a technique described by Grillo and colleagues in 1982. There were no operative deaths, and good (64\%) to excellent (26\%) results were obtained in $90 \%$ of cases. Importantly, considering the idiopathic cause of this inflammatory process, these favorable results were well maintained in long-term follow-up.

Our Toronto group has had a small experience with the 1-stage surgical management of ILTS. Our observations concerning clinical presentation, natural history, and surgical pathology mirror those reported by Ashiku and colleagues. ${ }^{1}$ A few variations in management are noted.

We reported initial experience with 2 cases of ILTS in $1986^{2}$ and with 9 cases of ILTS among a group of 53 patients undergoing a 1-stage cricotracheal resection for subglottic stenosis in 1992. ${ }^{3}$ Our original technique of partial cricoid resection, described in $1975,{ }^{4}$ differed from that of Grillo and colleagues in that the subglottic mucosa was divided transversely at the upper line of transection and anastomosed to the distal tracheal margin. Some of the anterior aspect of the posterior cricoid plate was usually rongeured away to widen and facilitate the end-to-end anastomosis. A posterior tracheal mucosal flap was used only in those cases in which the upper resection margin included an interarytenoid scar. Interarytenoid scarring was 
present in only 1 of our 9 reported cases. Good-to-excellent results were achieved and maintained in all 9 patients.

In patients requiring temporary postoperative airway support, we have used a Montgomery T tube as an alternative to a distal tracheostomy tube. The upper tracheal arm of the $\mathrm{T}$ tube is placed about $1 \mathrm{~cm}$ above the vocal cords because the anastomosis lies within millimeters of the inferior margin of the vocal folds. A T tube has the advantage over an open tracheostomy of providing a closed and wellhumidified airway.

We have also had some experience with cricotracheal resection and primary reconstruction in 5 patients with cicatricial subglottic stenosis caused by Wegener granulomatosis. ${ }^{5}$ In all 5 instances, the acute inflammatory process had subsided, and the collagen disorder appeared to be well controlled with immunosuppressive medication other than high-dose steroids. In contrast to the unfavorable results in
6 patients reported by Akishu and colleagues, ${ }^{1}$ all 5 of our patients were significantly benefited over long-term followup. $^{5}$

\section{References}

1. Ashiku SK, Kuzucu A, Grillo HC, Wright CD, Wain JC, Lo B, et al. Idiopathic laryngeal stenosis: effective definitive treatment with laryngotracheal resection. J Thorac Cardiovasc Surg. 2004;127:99-107.

2. Pearson FG, Brito-Filomeno L, Cooper JD. Experience with partial cricoid resection and thyrotracheal anastomosis. Ann Otol Rhinol Laryngol. 1986;95:582-5.

3. Maddaus MA, Toth JLR, Gullane PJ, Pearson FG. Subglottic tracheal resection and synchronous laryngeal reconstruction. $J$ Thorac Cardiovasc Surg. 1992;104:1443-50.

4. Pearson FG, Cooper JD, Nelems JM, Van Nostrand AWP. Primary tracheal anastomosis after resection of the cricoid cartilage with preservation of recurrent laryngeal nerves. J Thorac Cardiovasc Surg. 1975;70:806-16.

5. Herridge MS, Pearson FG, Doowney GPP. Subglottic stenosis complicating Wegener's granulomatosis: surgical repair as a viable treatment option. J Thorac Cardiovasc Surg. 1996;111:961-6.

\section{The Journal of Thoracic and Cardiovascular Surgery Conflict of Interest Policy}

To assure fairness to authors submitting work for consideration in The Journal of Thoracic and Cardiovascular Surgery, a mechanism exists for managing conflicts of interest. The editor and each of the section editors complete a "Conflict of Interest" form that identifies any and all relationships with commercial and other academic entities. When the editor has a potential conflict because of a relationship with another entity or author, the editor appoints an alternate editor from among the section editors or editorial board members who assumes the entire responsibility for final decisions on the manuscript in question. The editor does not read the reviews that are submitted nor engage in discussing the manuscript prior to the final decision. When the conflict of interest involves a section editor, a "guest section editor" is appointed who fills the role normally played by the conflicted section editor. All members of the editorial board and reviewers are asked to indicate any conflict of interest when they agree to review a manuscript. 